IZA DP No. 5240

Friends' Networks and Job Finding Rates

Lorenzo Cappellari

Konstantinos Tatsiramos

October 2010 


\title{
Friends' Networks and Job Finding Rates
}

\author{
Lorenzo Cappellari \\ Università Cattolica, Milan \\ and IZA

\section{Konstantinos Tatsiramos} \\ $I Z A$
}

\author{
Discussion Paper No. 5240 \\ October 2010
}

\author{
IZA \\ P.O. Box 7240 \\ 53072 Bonn \\ Germany \\ Phone: +49-228-3894-0 \\ Fax: +49-228-3894-180 \\ E-mail: iza@iza.org
}

Any opinions expressed here are those of the author(s) and not those of IZA. Research published in this series may include views on policy, but the institute itself takes no institutional policy positions.

The Institute for the Study of Labor (IZA) in Bonn is a local and virtual international research center and a place of communication between science, politics and business. IZA is an independent nonprofit organization supported by Deutsche Post Foundation. The center is associated with the University of Bonn and offers a stimulating research environment through its international network, workshops and conferences, data service, project support, research visits and doctoral program. IZA engages in (i) original and internationally competitive research in all fields of labor economics, (ii) development of policy concepts, and (iii) dissemination of research results and concepts to the interested public.

IZA Discussion Papers often represent preliminary work and are circulated to encourage discussion. Citation of such a paper should account for its provisional character. A revised version may be available directly from the author. 
IZA Discussion Paper No. 5240

October 2010

\section{ABSTRACT}

\section{Friends' Networks and Job Finding Rates ${ }^{*}$}

We investigate the effect of social interactions on labor market outcomes using a direct measure of social contacts based on information about individuals' three best friends and their characteristics. We examine the effect of the number of employed friends on the transition from non-employment to employment, and we find the existence of significant network effects at the individual level. An additional employed friend increases the probability of finding a job by 3.7 percentage points. This finding is robust to specifications that address the endogeneity of friends' employment status, which may be induced by correlation with unobserved individual attributes and feedback effects. Considering labor market outcomes, we find evidence of higher wages and employment stability for those with more employed friends, which is consistent with networks acting as an information transmission mechanism.

JEL Classification: J64

Keywords: networks, unemployment, friendship ties

Corresponding author:

Konstantinos Tatsiramos

IZA

P.O. Box 7240

53072 Bonn

Germany

E-mail: tatsiramos@iza.org

\footnotetext{
*We are grateful to Michele Belot, Pierre Cahuc, John Ermisch, Marco Francesconi, Dan Hamermesh, Yannis Ioannides, Francis Kramarz, Peter Kuhn, Erzo Luttmer, Luca Merlino, Pierre-Carl Michaud, Sol Polachek, Fabien Postel-Vinay, Stephen Jenkins, Joerg Stoye, Jan van Ours, and participants at the IZA Prize Conference in D.C., the ESPE conference in Essen, the CRETE conference in Tinos and seminars at IZA, BeNa in Berlin, Universita Cattolica and Biccoca in Milan, Copenhagen and Tilburg. The usual disclaimers apply.
} 


\section{Introduction}

Search in the labor market involves the acquisition of information about available job opportunities, which requires time and effort. Social networks have for long been considered as an important source of information for job seekers (see e.g. Rees, 1966; Montgomery, 1991 in economics; and Granovetter, 1995; Petersen et al., 2010 in sociology). A number of early studies have documented the widespread use of friends and relatives as a job search method (see Montgomery, 1991 and Ioannides and Loury, 2004 for reviews). Recent studies have looked at the effect of social interactions on employment and wages using indirect measures, such as geographical proximity or group affiliation, to define the relevant social network (e.g. Topa, 2001; Munshi, 2003; Weinberg et al., 2004; Bayer et al., 2008; Dustmann et al., 2010). ${ }^{1}$

In this paper, we investigate the importance of network effects in the labor market using direct information on social interactions. We develop a measure of the relevant social network of each individual which is based on information from the British Household Panel Survey (BHPS) about each of the respondent's three best friends and their characteristics. Using this information, we can construct a measure of the quality of the network based on the employment status of the friends. To the best of our knowledge, this is the first paper that uses direct information on social interactions in estimating the effect of networks on labor market outcomes. Unlike previous research, we do not rely on the identification assumption that individuals within a given group - e.g. neighborhood or firm - actually know each other and are members of the same network, which is nontestable. The focus of our empirical analysis is to identify the effect of the number of

\footnotetext{
${ }^{1}$ Ioannides and Topa (2010) review the recent literature on social interactions and job matching based on neighborhood effects.
} 
employed friends on job finding rates based on the transition from non-employment to employment across two years. Due to the panel structure of our data, the measure of network quality - the number of employed friends - is predetermined at the time of the observed transition, which avoids the reflection problem (Manski, 1993).

The motivation behind using the number of employed friends as a measure of the quality of the social network is that employed social contacts are expected to be better informed about job opportunities available in the market and to pass this information to non-employed network members. The better, therefore, the employment status of an agent's connections, the more likely that is the agent to receive information about employment opportunities. This leads to a positive correlation between the employment status of the agents in a network. Our analysis, therefore, offers direct evidence to theoretical work which examines the implications of networks on employment dynamics (Montgomery, 1991; Calvó-Armengol and Jackson, 2004; Bramoullé and Saint-Paul, 2009).

Identification of social network effects is complicated for a number of reasons. ${ }^{2}$ First, any effect of the number of employed friends on job finding rates might be due to the presence of correlated unobservables. Unobserved individual attributes can be correlated between an individual and his or her contacts because of positive sorting. For instance, more able and motivated individuals have better employment prospects and are more likely to have employed friends. Generally, social interactions are more likely to emerge among individuals that share some relevant traits - such as education or ethnicity

\footnotetext{
2 The identification of social interactions is discussed by Manski (1993, 2000), Moffitt (2001), Bramoullé et al. (2009) and in the comprehensive review by Blume et al. (2010).
} 
- or are characterized by similar tastes or constraints. ${ }^{3}$ When these traits and tastes are unobservable to the researcher and correlated with the outcomes of interest the estimated effect will be biased and cannot be attributed to a network effect. Our identification strategy exploits the panel dimension of our data, which provides variation in the employment status of friends and the outcomes for a given individual over time. This allows us to control for individual fixed effects. The main identification assumption is that any correlation between the number of employed friends and individual unobserved traits is due to traits that do not vary over time. This assumption rules out any correlation due to time-varying unobserved attributes. We investigate the sensitivity of our results to the inclusion of time-varying observed heterogeneity, and we show that our findings are robust. Correlation in unobservables may also arise because of the presence of local economic shocks (e.g. a plant closing in the local area) that affect both the individual and his or her friends. We address this issue by controlling for the local economic conditions using the unemployment rates in the travel-to-work area.

The second complication in the estimation of the network effects is that the composition and quality of the network might change in response to individual's labor market status. This feedback from being non-employed to the number of employed friends might arise if, for instance, staying longer out of employment leads to fewer contacts with those employed. We provide evidence that our findings are robust to the existence of an endogenous network and, if anything, they can be seen as a lower bound.

Our results indicate the existence of significant network effects at the individual level. An additional employed friend increases the probability to find a job by 3.7

\footnotetext{
${ }^{3}$ For a model of friendship formation stressing the role of 'types' similarities, see Currarini et al. (2009). An empirical investigation of friendship formation is provided by Marmaros and Sacerdote (2006).
} 
percentage points. In addition, the job-finding rate increases with the number of employed friends, with individuals being 11 percentage points more likely to become employed when they have three employed friends than having none. We also find that an additional employed friend among those who find a job is associated with a 6.2 percent increase in wages and a reduction in the probability to exit from subsequent employment of 5.1 percentage points. We interpret these additional findings as suggestive evidence of networks operating as information transmission mechanisms.

The remainder of the paper is organized as follows. Section 2 discusses how this paper is related to the social network theories of the labor market and the existing empirical literature. Section 3 describes the data and the empirical strategy. We report the main results in Section 4, discuss our findings in relation to the potential mechanisms that can explain network effects in Section 5 and conclude in Section 6.

\section{Theoretical Framework and Empirical Literature}

The analysis in this paper offers direct empirical evidence on the role of employed contacts on job finding probabilities. A number of theoretical contributions have modeled the impact of social interactions on employment transitions. These studies emphasize the role of the employment status of the contacts in the network (Montgomery, 1991; CalvóArmengol, 2004; Calvó-Armengol and Jackson, 2004; Bramoullé and Saint-Paul, 2009; Galeotti and Merlino, 2010). ${ }^{4}$ Employed network members receive information about vacancies which they do not need for themselves and pass on to their unemployed contacts; they may be generally better informed about employment opportunities available in the market; or they may directly provide job referrals to employers. All these

\footnotetext{
${ }^{4}$ Ioannides and Loury (2004) provide a comprehensive review of the literature.
} 
mechanisms imply a transmission of information between employed and unemployed network members that is beneficial to the job search process of the latter. Therefore, the core prediction from the theoretical literature is that the better the employment status of an individual's connections, the more likely he or she is to receive information about jobs, which leads to a positive correlation between the employment status of connected individuals in a network.

Our work relates to the growing empirical literature that tries to identify the labor market effects of social networks. A major challenge for most studies is the definition of the network due to the lack of information on social interactions. ${ }^{5}$ One stream of literature relies on self-reported information about the use of contacts while searching for a job (see Loury, 2006 and Pellizzari, 2010 for recent examples in the literature). In this case, researchers have information on the existence of social ties, but typically do not observe the quality of such ties (in particular their employment status), which is key in testing the predictions of theoretical models. Moreover, the effect of informal contacts may stem from improvement in match quality or from selection effects of workers with limited access to alternative search channels.

Alternatively, research strategies based on geographical proximity and group affiliation have been proposed. A common trait of these studies is that in the absence of direct information on social ties, networks are assumed to operate along some observable dimensions, such as the neighborhood or the firm. Practically, researchers generate clusters of agents based on group membership and assume that individuals know each

\footnotetext{
${ }^{5}$ Data on actual links within a network have been recently used by Calvó-Armengol et al. (2009) to study educational outcomes. Using the US Add Health survey, they are able to construct complete network of friends in high schools and are then able to relate network characteristics to measures of educational success, separating network from peer effects.
} 
other within these groups. Examples of studies that use geographic proximity at the neighborhood level to define networks include Topa (2001), Weinberg et al. (2004), Bayer et al. (2008), Hellerstein et al. (2008) and Schmutte (2010). These studies find significant effects of networks on employment and wages. ${ }^{6}$ Studies that define networks based on group affiliation include Cingano and Rosolia (2006), who use data from the Italian social security archive and define contact networks at the firm level as the set of individuals who had been working together prior to displacement, Dustmann et al. (2010) who use German linked employer-employee data to study ethnicity based job referral networks, and Munshi (2003) who defines networks at the origin-community level to identify job networks among Mexican migrant in the U.S. labor market.

Finally, another empirical strategy relies on family networks identified from population-wide employer-employee data set. Kramarz and Nordström Skans (2009) study the school-to-work transitions of young Swedish and find that job referrals from parents are indeed very frequent, especially for males at the low end of the skill distribution. Although family networks define in a direct way the connection between network members they are more specific and refer to a subset of the potential social interactions that might be relevant.

\section{Data and Empirical Strategy}

\subsection{Data}

We use data from the British Household Panel Survey (BHPS) between 1992 and 2003. The BHPS is a representative sample of British households which follows individuals over time, allowing identification of yearly transitions across labor market states. In

\footnotetext{
${ }^{6}$ Van der Klaauw and van Ours (2003) use neighborhoods to study the effect of networks in the context of welfare transitions. Welfare dependency and social networks are also studied by Bertrand et al. (2000).
} 
addition to this, the BHPS contains a special section on social networks, which we exploit for estimating network effects on job finding rates. Starting from wave 2 (1992), respondents were asked at each even-numbered wave to report information on their three best friends. Besides details about best friends' gender and age, the BHPS provides information on the employment status of friends. Therefore, we can observe that part of the network closest to the BHPS respondent (the three best friends), and we are able to characterize the employment intensity within that portion.

Since information on friends is retrieved at every even-numbered wave, we are able to relate the employment status of friends at wave $t(t=1992,1994,1996, \ldots, 2002)$ to the employment transitions of BHPS respondents between waves $t$ and $t+1$. We select a sample of individuals aged 18-65 and not in full time education at any even-numbered wave whose three best friends also belong to the same age range. This results in 10,911 individual observations (5,296 men and 5,615 women) with a total of 36,610 person-year observations. Since our focus is on yearly transitions from non-employment into employment (including self-employment) from one year to the next, we further select individuals who are not employed in the survey year and whose employment status in the subsequent year is observed. Finally, we exclude individuals who do not report information on all three friends. ${ }^{7}$ Our final estimating sample consists of 3,196 nonemployed individuals with a total of 6,479 person-year observations. Half of the individuals are observed as non-employed more than once in the sample.

Some relevant demographic information for the estimating sample is presented in Panel A of Table 1, in connection with the demographic characteristics of the three best

\footnotetext{
${ }^{7}$ In Section 4.3 we investigate the sensitivity to the exclusion of those individuals with missing information on their friends.
} 
friends. The table shows that there is a certain extent of assortative mating among friends in terms of both gender and age. The proportion of women whose first best friend is a woman is 83 percent, and a similar incidence (81 percent) characterizes men. As we move from the first to the third best friends, assortative mating remains high among women (79 percent have the third best friend who is of the same gender), while it decreases somehow more evidently for men, where the proportion of cases whose third best friend is men is 71 percent. We can observe patterns of assortative mating among friends also in the case of age, where the average age of friends grows with the age of the respondent. Note, however, that we have truncated the distribution of friends' age between 18 and 65, which explains why the ordering between respondents and their friends' ages reverts as we consider older respondents in our sample.

In Panel B of Table 1 we provide some summary statistics on the job finding probabilities in the sample. On average, about 20 percent of non-employed individuals make a transition from non-employment to employment from one year to another. ${ }^{8}$ The lower part of Table 1 provides evidence on the association between the number of employed individuals in the group of the three best friends and transitions from nonemployment to employment. As can be seen, the association is strong, with the exit rate from non-employment that more than triples when moving from zero to three employed friends. Moreover, patterns appear to be rather similar for women and men.

\subsection{Empirical Strategy}

We model the associations singled out in Table 1 by means of regression models for the

\footnotetext{
${ }^{8}$ The year-to-year job finding rate is much higher for the unemployed (42 percent) and lower for the inactive (15 percent).
} 
probability of transitions from non-employment into employment.

Let $E_{i t}$ be a dummy indicator of respondent's $i$ employment status in year $t$, and let $N E F_{i t}$ denote the number of employed friends of individual $i$ in year $t$, a variable that can take values from 0 to 3 . The employment dummy takes on value one for respondents that are either full-time employees, part-time employees or self-employed, and value zero for those who are either unemployed (ILO definition) or out of the labor force. Our baseline specification is

$$
\operatorname{Pr}\left(E_{i, t+1} \mid E_{i, t}=0\right)=F\left(X_{i, t}^{\prime} \beta_{1}+\delta N E F_{i, t}+u_{i}\right)
$$

where $X_{i, t}$ is a vector of controls. The vector of individual characteristics includes timevarying and time-invariant regressors. The time-varying regressors include the local unemployment rate defined at the travel-to-work area level, age and dummies for the region of residence, the survey year, living as a couple, having one, two or more children, experiencing health problems, depression and being a smoker. The time-invariant regressors include a gender dummy, education (highest qualification attained) and ethnicity (categorized in nine groups) dummies. We also include in vector $X$ the individual characteristics of each of the three friends for which we have information; age and gender.

We estimate the transition equation in (1) by forming a sample of non-employed individuals at each even wave ( $\mathrm{t}=1992,1994,1996, \ldots$, 2002). For estimation we adopt a fixed effect logit approach, which eliminates the unobserved effect $u_{i}$, which is fixed over time. In our sample, we observe multiple non-employment spells for each individual with the number of employed friends varying over time and across these spells. We use this variation to control for individual unobserved heterogeneity that might be correlated 
with the main variable of interest, the number of employed friends. The sample size is reduced substantially due to conditioning on those individuals who are observed with multiple spells and with transitions from non-employment to employment over time.

The presence of unobserved heterogeneity induces serial correlation in the employment process, which may imply that sample selection is endogenous. Note, however, that we integrate out time-invariant unobserved heterogeneity using the fixed effect logit estimator. Moreover, to the extent that those found out of employment in a given year have an unobserved propensity to find a job that is lower than the average in the population, any remaining bias is likely to produce attenuation in the effect under estimation.

\section{Results}

\subsection{Empirical Correlations}

We first present some regression-based correlations between the number of employed friends and the transition into employment to have a benchmark for comparison with the fixed effect estimates that follow. Column 1 of Table 2 presents the estimates of a pooled logit regression without additional controls. We find that the number of employed friends exhibits a positive and significant effect on the transition into employment. The marginal effect suggests that having an additional employed friend increases the job finding probability by 6.4 percentage points (p.p). ${ }^{9}$ In Columns 2 and 3 we investigate the sensitivity of this finding to the inclusion of individual and friends' characteristics. With the inclusion of friends' characteristics (age and gender) the marginal effect reduces to

\footnotetext{
${ }^{9}$ Marginal effects for both the pooled logit and the fixed effect logit of the next section are computed as $\beta_{\text {nef }} p(1-p)$, where $\beta_{\text {nef }}$ is the estimated coefficient on the number of friends, while $p$ is the average sample predicted probability.
} 
5.9 p.p and after controlling for individual observed characteristics, the marginal effect becomes 6.0 p.p. This suggests that only a small part of the effect is due to a correlation between the number of employed friends and observed characteristics. Taking into account the unconditional job finding rate of 20.28 percent, the effect of an additional employed friend is sizeable and corresponds to approximately a 33 percent increase. Estimating the same pooled logit model separately for the unemployed and inactive, we find that an additional employed friend increases the job finding rate by 7.0 p.p. for the unemployed and by 5.0 p.p. for the inactive.

Non-linear effects - The above analysis imposes a linearity assumption on the effect of the number of employed friends. We next estimate the pooled probit model allowing for a non-linear effect by defining dummies for having one, two or three employed friends. The results presented in Column 4 of Table 2 show that having one employed friend significantly increases the probability to enter employment in the next year by 6.2 p.p compared to having no employed friends, while having two or three employed friends increases the job finding probability by 10.3 p.p and 18.1 p.p, respectively. We also experimented with quadratic trends and with specifications accounting for the effect of one additional employed friend, and found no clear evidence of convexities in the network effect.

\subsection{Unobserved Individual Heterogeneity}

The results presented so far establish the existence of a correlation between the employment status of friends. Non-employed individuals who have more employed friends are more likely to find a job. One concern with this finding is that unobserved 
individual characteristics might affect both the probability of having friends who are employed and their own probability of becoming employed. For instance, individuals who are more attached to the labor market might have a higher propensity to find a job and at the same time have friends who are more likely to be employed. This would lead to an upward bias on the effect of the number of employed friends. As discussed in Section 3, we address this by estimating equation (1) using a fixed effect logit approach.

The first column of the top panel (FE-1) of Table 3 shows that even after controlling for fixed effects the coefficient of the number of employed friends indicates a positive and significant effect on job finding probability. An additional employed friend increases the transition probability by 3.7 p.p. This effect is lower compared to the pooled estimation, which suggests a positive correlation between unobserved individual heterogeneity and having employed friends, which leads to an upward bias. Nevertheless, the effect remains significant and large. This finding is consistent with the core prediction from the theoretical literature that the better the employment status of an individual's connections, the better his or her employment prospects (Calvó-Armengol, 2004; CalvóArmengol and Jackson, 2004; Bramoullé and Saint-Paul, 2009; Galeotti and Merlino, 2010).

The non-linear specification of the FE-1 estimation in the lower panel of Table 3 shows that the effect is higher - and significant - when all friends are employed. This finding is consistent with the theoretical predictions of Calvó-Armengol and Jackson (2004), according to which, more employed contacts reduce the competition within the network, so we should expect a larger effect. To the contrary, when the network has more unemployed friends, then any new information about job vacancies that might arrive is 
more likely to be kept by the individual who receives it and less likely to be passed on to other members of the network.

The fixed effect estimation (FE-1) assumes that only fixed unobserved individual characteristics can be correlated with the employment status of friends. It could be the case, however, that time-varying characteristics might change when one enters nonemployment and this change might be correlated with friends' characteristics. For instance, it is possible that behavior such as smoking, drinking or depression might change upon entering non-employment, which might also affect the friendship ties of the unemployed. In order to test for the presence of such a correlation, we estimate our model by excluding all the time-varying covariates (FE-2). Our maintained assumption is that if observed and unobserved time-varying heterogeneity are correlated, then finding that our estimates are not sensitive to time-varying regressors would signal that they are also likely to be robust to time-varying unobserved heterogeneity. The second column of Table 3 shows that after excluding all the time-varying regressors the fixed-effect estimate is very similar (marginal effect of 3.8) with the one that includes the timevarying regressors (marginal effect of 3.7).

\subsection{Robustness Analysis}

We investigate the robustness of our main results to a number of additional issues. First, correlation in unobservables may arise not only due to individual unobserved characteristics but also because of the presence of local economic shocks that might affect both the number of employed friends and the job finding probability. Second, we consider the situation in which the network is endogenous, so that the composition of the 
network may change in response to individual's labor market status. Finally, we check the sensitivity of our findings with respect to the missing information on friends, and the inclusion of the length of the spell.

Local economic conditions - Starting with the local economic conditions we consider their importance for our findings in two ways. First, we estimate our baseline model excluding the local unemployment rate, which is defined at the travel-to-work area. The coefficient estimate from FE-3 in Table 3 remains the same compared to the main specification (FE-1), which suggests that our main finding is not sensitive to the local economic conditions. Second, we estimate our baseline model including, as an additional control, the percentage of benefit claimants by occupation and region. The idea is that individuals who work in the same occupation as their friends are more likely to be subject to correlated shocks that might not be completely captured by an aggregate local unemployment rate. The percentage of benefit claimants by occupation in the region of residence captures those local occupational specific shocks that might affect members of the same network. We only have this information for the years 1996-2000, so we perform this estimation with the relevant sub-sample. Due to the reduced sample size, we are not able to estimate the model with fixed effects. Based on the estimation on the pooled sample, we find that after controlling for the percent of benefit claimants, the marginal effect of the number of employed friends on the sub-sample of observations within 19962000 remains unchanged at 0.04 (4 p.p).

Endogenous networks - The estimation of the fixed effects model relies on variation over time of the employment status of friends, assuming no feedback effects. This rules out the case of a feedback from being non-employed to the number of 
employed friends, which might arise if, for example, staying longer out of employment leads to fewer contacts with employed people. In addition, given that our sample is based on the stock of non-employed at time $t$ with differences in the length of elapsed duration, this feedback might lead to dynamic selection with those having a shorter duration also having more employed friends. This type of selection might result in a spurious correlation between the number of employed friends and job finding rates as those with shorter duration in non-employment are also more likely to find a job.

Starting from the possible selection due to stock-sampling, we examine the effect of the elapsed duration in non-employment on the number of employed friends. Although this does not address selection in a regression framework, it provides evidence as to whether those with longer non-employment spells have systematically fewer employed friends. Given the panel structure of our data, we estimate a linear fixed effects model, which eliminates the unobserved individual characteristics that might be correlated with both the number of employed friends and the length of time in non-employment. The top panel of Table 4 shows that the elapsed duration in months in non-employment is not statistically significant in explaining the number of employed friends. This provides sufficient evidence that our sample is not selected in way that might lead to a spurious relation between number of employed friends and job finding rates. ${ }^{10}$ We also investigate the sensitivity of our estimates from equation (1) to the inclusion of the length of time in the current labor market state for the sample of non-employed. The estimation FE-4 in Table 3 shows that controlling for the length out of employment increases the marginal effect from 0.037 to 0.042 . This suggests that any correlation between the length of time

\footnotetext{
${ }^{10}$ The OLS result (not reported) is negative and significantly different from zero, which suggests that any correlation is due to unobserved characteristics.
} 
in non-employment and the number of employed friends is likely to lead to a downward bias.

We also estimate equation (1) using lag values of the number of employed friends. If feedback effects from non-employment spells may induce depletion in the stock of friends in the base year of a transition, using the number of employed friends in the year before provides a measure of networks that is less prone to this type of effect. The coefficient estimate from the fixed effect logit in the second panel of Table 4 using the lag number of employed friends is larger compared to the estimate from Table 3 (FE1), which refers to the current number of friends. The estimated marginal effect is 6.3 p.p. (3.7 p.p. in Table 3), which suggests that our main estimates from Table 3 can again be seen as a lower bound of the effect of networks on job finding rates.

Missing friends - Finally, we check the sensitivity of our main findings to the missing information on friends. Every individual in the survey is asked to provide information on his or her three best friends; but not everyone reports information on all their friends. Considering the sample which includes those with missing information on their friends, we include dummy variables by the type of information that is missing for each friend as additional controls. The last column in Table 3 shows that main effect of the number of employed friends is unchanged when we consider this larger sample. The marginal effect is slightly larger (0.041 instead of 0.037 of FE-1) and is statistically significant.

\subsection{Labor market outcomes}

Given the panel dimension of our data, we are able to investigate the effect of networks on labor market outcomes for those who find a job. We consider re-employment wages 
and the stability in employment by modeling the probability of exiting from employment back to non-employment over the next year.

Column 1 in Table 5 shows that the number of employed friends has a significant and positive effect on re-employment wages. An additional employed friend increases wages for those who become employed in the next year by 6.2 percent. In addition, having one (three) employed friend(s) compared to having no employed friends increases wages by 11.6 (22.2) percent. The second column of Table 5 shows that an additional employed friend not only increases wages but also reduces the probability to exit subsequent employment by 5.1 p.p. As shown in the lower panel of Table 5, having one friend does not lead to a significant difference in exit rates, but those who have two or three friends employed compared to none are significantly more likely to remain employed. While both these results suggest positive network effects on labor market outcomes one has to view them with some caution as those who find a job might be positively selected among the non-employed.

\section{Discussion}

There are a number of potential mechanisms through which employed friends might affect job finding probabilities. The first mechanism is related to information transmission of available jobs from the employed to the non-employed contacts of the network (e.g. Calvó-Armengol and Jackson, 2004; Bramoullé and Saint-Paul, 2009). The second is related to peer-effects and social norms. Social norms might exert pressure on the unemployed workers to find a job. Stutzer and Lalive (2004) provide evidence that social norms ('worth ethic') speed up transitions out of unemployment. To the extent that 
the relevant social group is formed by the best friends, our findings may reflect the pressure that employed friends exert on non-employed network members. A third mechanism that might explain the findings is leisure complementarities. When the friends of an unemployed person are all employed, this will lower the value of leisure if enjoying leisure requires the presence of others, which might lower the reservation wage. Jenkins and Osberg (2004) show the effect of leisure coordination on the happiness of couples.

As a way to assess the relevance of peer-pressure and leisure complementarities as explanations of our findings, we exploit data on life satisfaction and satisfaction with the use of leisure, which are available in the BHPS. If non-employed individuals experience pressure from having all their friends employed or derive disutility from the fact that they have 'nobody to play with' when they have time free from market work, we should expect a negative association between the number of employed friends and satisfaction with life in general and leisure. We can actually estimate these associations by regressing life satisfaction and satisfaction with leisure of the non-employed on the number of their employed friends. The findings in Table 6 - both for the OLS and FE estimations - suggest that the number of employed friends does not have any effect on either measures of satisfaction.

In addition, for both the peer-effect and leisure complementarity hypotheses, we expect a lower reservation wage when the number of employed friends is higher. In fact, according to both interpretations, employed friends make non-employment spells more painful, so that non-employed network members should try to speed up the exit from non-employment, which can be done by lowering reservation wages and increasing search effort. In turn, lower reservation wages should correspond to lower wages upon re- 
employment. Conversely, the information hypothesis would suggest that the number of employed friends should lead to better employment opportunities and higher wages, to the extent that networks convey superior information on job offers relative to alternative job search channels. ${ }^{11}$ The evidence that the number of employed friends increases wages and the stability in employment that we provided in Section 4.4 is, therefore, suggestive of networks operating as information transmission mechanisms.

\section{Conclusion}

This paper investigates the effect of social interactions on labor market outcomes using a direct measure of social contacts based on individuals' best friends and their characteristics. Using data from the BHPS, we identify the effect of social networks by examining the effect of the number of employed friends on the transition from nonemployment to employment. We provide evidence that employed friends increase the probability of finding a job. An additional employed friend increases the probability of finding a job by 3.7 percentage points, which is a sizeable effect. In addition, having all friends employed compared to no employed friends leads to the greatest effects. These results are robust to a number of specifications that address the potential endogeneity of the number of employed friends due to correlated unobservables and feedback effects.

We also investigate the potential mechanisms through which employed friends might affect job finding probabilities, considering three mechanisms: information transmission, peer-effects or social norms, and leisure complementarities. To distinguish between these different channels, we consider the relation of the number of employed

\footnotetext{
${ }^{11}$ Ioannides and Soetevent (2006) show in a calibrated matching model with random social network that on average workers who are better connected socially experience lower unemployment rates and receive higher wages.
} 
friends with wages, subsequent employment stability and satisfaction with life and leisure. We find that having more employed friends is associated with wage gains and more stable employment, while there is no effect on satisfaction. We interpret this as evidence of the information transmission mechanism through which social networks operate. 


\section{References}

Bayer, P., Ross, S.L. and Topa, G. (2008) Place of Work and Place of Residence: Informal Hiring Networks and Labor Market Outcomes, Journal of Political Economy, 116(6), 1150-1196.

Bertrand, M., Luttmer, E.F.P. and Mullainathan S. (2000) Network Effects and Welfare Cultures, Quarterly Journal of Economics, 115(3), 1019-1055

Blume, L.E., Brock, W.A., Durlauf, S.N. and Ioannides, Y.M. (2010) Identification of Social Interactions in Benhabib, J., Bisin, A. and Jackson, M. (eds) Handbook of Social Economics (forthcoming).

Bramoullé, Y. and Saint-Paul, G. (2009) Social Networks and Labor Market Transitions, Labor Economics, 17(1), 188-195.

Bramoullé, Y., Djebbari, H. and Fortin, B. (2009) Identification of Peer Effects Through Social Networks, Journal of Econometrics, 150(1), 41-55.

Calvó-Armengol, A. (2004) Job Contact Networks, Journal of Economic Theory, 115(1), 191-206.

Calvó-Armengol, A. and Jackson M.O. (2004) The Effects of Social Networks on Employment and Inequality, American Economic Review, 94(3), 426-454.

Calvó-Armengol, A., Patacchini, E. and Zenou, Y. (2009) Peer Effects and Social Networks in Education, Review of Economic Studies, 76, 1239-1267

Cingano, F. and Rosolia, A. (2006) People I Know: Workplace Networks and Job Search Outcomes, Bank of Italy Discussion Paper 600.

Currarini, S., Jackson, M.O. and Pin, P. (2009) An Economic Model of Friendship: Homophily, Minorities, and Segregation, Econometrica, 77(4), 1003-1045. 
Dustmann, C., Glitz, A. and Schönberg, U. (2010) Referral-based Job Search Networks, unpublished paper, Department of Economics, University College London.

Galeotti A. and Merlino L.P. (2010) Endogenous Job Contact Networks, ISER Working Paper No. 2010-14, University of Essex.

Granovetter, M. (1995) Getting a Job: A Study of Contacts and Careers, 2nd edition, University of Chicago Press: Chicago.

Hellerestein, J.K., McInerney, M. and Neumark, D. (2008) Measuring the Importance of Labor Market Networks, IZA Discussion Paper No. 3750.

Ioannides, Y.M. and Loury, L.D. (2004) Job Information Networks, Neighborhood Effects, and Inequality, Journal of Economic Literature, 42(4), 1056-1093.

Ioannides, Y.M. and Soetevent, A.R. (2006) Wages and Employment in a Random Social Network with Arbitrary Degree Distribution, American Economic Review, 96(2), 270-274.

Ioannides, Y.M. and Topa, G. (2010) Neighborhood Effects: Accomplishments and Looking Beyond Them, Journal of Regional Science, 50(1), 343-362.

Jenkins, S. and Osberg, L. (2004) Nobody to Play With? The Implications of Leisure CoOrdination, in Hamermesh, D. and Pfann, G. (eds) The Economics of Time Use: Contributions to Economic Analysis (CEA) No. 271, Elsevier.

Kramarz, F. and Nordström Skans, O. (2009) With a Little Help from my ... Parents? Family Networks and Youth Labor Market Entry, unpublished manuscript.

Loury, L.D. (2006) Some Contacts Are More Equal than Others: Informal Networks, Job Tenure, and Wages, Journal of Labor Economics, 24(2), 299-318. 
Manski, C.F. (1993) Identification of Endogenous Social Effects: The Reflection Problem, Review of Economic Studies, 60(3), 531-542.

Manski, C.F. (2000) Economic Analysis of Social Interactions, Journal of Economic Perspectives, 14(3), 115-136.

Marmaros, D. and Sacerdote B. (2006) How do Friendships Form?, Quarterly Journal of Economics, 121(1), 79-119.

Moffitt, R.A. (2001) Policy Interventions, Low-Level Equilibria, and Social Interactions in Durlauf, S.N. and Peyton Young, H. (eds) Social Dynamics, Cambridge MA: MIT Press.

Montgomery, J.D. (1991) Social Networks and Labor-Market Outcomes: Toward an Economic Analysis, American Economic Review, 81(5), 1408-1418.

Munshi, K. (2003) Networks in the Modern Economy: Mexican Migrants in the U.S. Labor Market, Quarterly Journal of Economics, 118(2), 549-599.

Pellizzari, M. (2010) Do Friends and Relatives Really Help in Getting a Good Job? Industrial and Labor Relations Review, vol. 63(3), 494-510.

Petersen, T., Saporta, I. and Seidel, M-D.L. (2010) Offering a Job: Meritocracy and Social Networks, American Journal of Sociology, 106(3), 763-816.

Rees, A. (1966) Information Networks in Labor Markets, American Economic Review, 56(1/2), 559-566.

Schmutte, I.M. (2010) Job Referral Networks and the Determination of Earnings in Local Labor Markets, unpublished paper, Department of Economics, Cornell University

Stutzer, A. and Lalive, R. (2004) The Role of Social Work Norms in Job Searching and Subjective Well-Being, Journal of the European Economic Association, 2(4), 696- 
719.Topa, G. (2001) Social Interactions, Local Spillovers and Unemployment, Review of Economic Studies, 68(2), 261-295.

van der Klaauw, B. and van Ours, J.C. (2003) From Welfare to Work: Does the Neighbourhood Matter? Journal of Public Economics, 87(5-6), 957-985.

Weinberg, B.A., Reagan, P.B. and Yankow, J.J (2004) Do Neighborhoods Affect Hours Worked? Evidence from Longitudinal Data, Journal of Labor Economics, 22(4), 891-924. 
Table 1: Summary Statistics.

Panel a): Demographic characteristics of sample respondents and their three best friends

\begin{tabular}{|c|c|c|c|c|c|c|}
\hline \multirow{3}{*}{ Own Characteristics } & \multicolumn{6}{|c|}{ Friends' characteristics } \\
\hline & \multicolumn{2}{|c|}{ First Best Friend } & \multicolumn{2}{|c|}{ Second Best Friend } & \multicolumn{2}{|c|}{ Third Best Friend } \\
\hline & & & & & & \\
\hline & Man & Woman & Man & Woman & Man & Woman \\
\hline Man & 81.16 & 18.84 & 75.66 & 24.34 & 71.6 & 28.4 \\
\hline \multirow[t]{3}{*}{ Woman } & 16.94 & 83.06 & 16.26 & 83.74 & 20.78 & 79.22 \\
\hline & \multicolumn{6}{|c|}{ Age } \\
\hline & Mean & S.D & Mean & S.D & Mean & S.D \\
\hline 18 to 24 & 23.49 & 7.44 & 23.38 & 7.23 & 23.42 & 7.14 \\
\hline 25 to 29 & 30.57 & 9.17 & 30.3 & 8.56 & 29.57 & 7.78 \\
\hline 30 to 34 & 34.7 & 8.81 & 34.04 & 8.27 & 33.76 & 8.44 \\
\hline 35 to 39 & 38.21 & 8.18 & 37.38 & 7.88 & 37.28 & 8.18 \\
\hline 40 to 44 & 41.87 & 7.95 & 40.81 & 7.76 & 40.9 & 8.03 \\
\hline 45 to 49 & 44.66 & 8.04 & 43.59 & 8.52 & 43.54 & 8.86 \\
\hline 50 to 54 & 47.1 & 9.6 & 47.16 & 10.01 & 46.61 & 10.23 \\
\hline 55 to 65 & 51.3 & 10.52 & 50.01 & 11.09 & 49.55 & 10.86 \\
\hline
\end{tabular}

Panel b): Number of employed friends and exit rates from non-employment

\begin{tabular}{lccc}
\hline & Full sample & Men & Women \\
\hline $\begin{array}{l}\text { Unconditional } \\
\text { Exit rate }\end{array}$ & 20.28 & 22.52 & 19.34 \\
& & & \\
Number of Employed & & & \\
Friends & & & \\
\hline 0 & 9.77 & 12.57 & 8.82 \\
1 & 15.44 & 17.83 & 14.63 \\
2 & 20.66 & 19.88 & 20.96 \\
3 & 28.28 & 30.47 & 26.95 \\
\hline
\end{tabular}

Notes: The sample consists of non-employed individuals in the even years between 1992-2003 for which information on friends is observed. 
Table 2: Pooled Sample Estimates.

Coef. M.E. t-ratio

(1)

$\begin{array}{lllll}0.399 & 0.064 & 10.86 & 0.367 & 0.059\end{array}$

Number of Employed Friends

$\begin{array}{lll}0.367 & 0.059 & 9.67\end{array}$

One Employed Friend

Two Employed Friends

Three Employed Friends

Controls - Friends

Controls - Individual

Log-Likelihood

Number of Individuals

Number of Observations
Coef. M.E. t-ratio

Coef. M.E. t-ratio

(4)

$\begin{array}{lll}0.373 & 0.060 & 9.16\end{array}$

$\begin{array}{lll}0.384 & 0.062 & 2.53\end{array}$

$\begin{array}{lll}0.639 & 0.103 & 4.35\end{array}$

$\begin{array}{lll}1.126 & 0.181 & 7.50\end{array}$

$\begin{array}{cccc}\text { No } & \text { Yes } & \text { Yes } & \text { Yes } \\ \text { No } & \text { No } & \text { Yes } & \text { Yes } \\ & & & \\ -3,181.36 & -3,010.68 & -2,742.21 & -2,740.89 \\ 3,196 & 3,196 & 3,196 & 3,196 \\ 6,479 & 6,479 & 6,479 & 6,479\end{array}$

Notes: Logit regressions for the transition from non-employment to employment. Coefficients, marginal effects and their t-ratio are reported. The sample consists of non-employed individuals in the even years between 1992-2003 for which information on friends is observed. Other regressors include individual and friend time-varying covariates (age, dummies for living as a couple, number of children (1, 2 or more), having health problems, experiencing depression, smoking, time and region dummies, and age of each friend), individual and friend time-invariant covariates (dummies for female for individual and each of his or her friends, dummies for levels of education, ethnicity) and local economic conditions (local unemployment rate at travel-to-work area). Standard errors are clustered at the individual level. The full specification is reported in Table A1. 
Table 3: Fixed Effect Estimates.

\begin{tabular}{|c|c|c|c|c|c|c|c|c|c|c|c|c|c|c|c|}
\hline \multirow[b]{3}{*}{ Number of Employed Friends } & \multicolumn{3}{|c|}{ FE-1 } & \multicolumn{3}{|c|}{ FE-2 } & \multicolumn{3}{|c|}{ FE-3 } & \multicolumn{3}{|c|}{ FE-4 } & \multicolumn{3}{|c|}{ FE-5 } \\
\hline & Coef. & M.E. & t-ratio & Coef. & M.E. & t-ratio & Coef. & M.E. & t-ratio & Coef. & M.E. & t-ratio & Coef. & M.E. & t-ratio \\
\hline & 0.166 & 0.037 & 2.04 & 0.171 & 0.038 & 2.10 & 0.166 & 0.037 & 2.04 & 0.188 & 0.042 & 2.26 & 0.191 & 0.041 & 2.57 \\
\hline Log-Likelihood & \multicolumn{3}{|c|}{-450.04} & \multicolumn{3}{|c|}{-453.21} & \multicolumn{3}{|c|}{-450.11} & \multicolumn{3}{|c|}{-437.81} & \multicolumn{3}{|c|}{-608.53} \\
\hline Number of Observations & \multicolumn{3}{|c|}{1,324} & \multicolumn{3}{|c|}{1,324} & \multicolumn{3}{|c|}{1,324} & \multicolumn{3}{|c|}{1,307} & \multicolumn{3}{|c|}{1,787} \\
\hline & \multicolumn{3}{|c|}{ FE-1 } & \multicolumn{3}{|c|}{ FE-2 } & \multicolumn{3}{|c|}{ FE-3 } & \multicolumn{3}{|c|}{ FE-4 } & \multicolumn{3}{|c|}{ FE-5 } \\
\hline & Coef. & M.E. & t-ratio & Coef. & M.E. & t-ratio & Coef. & M.E. & t-ratio & Coef. & M.E. & t-ratio & Coef. & M.E. & t-ratio \\
\hline One Employed Friend & 0.371 & 0.082 & 1.39 & 0.389 & 0.086 & 1.46 & 0.371 & 0.082 & 1.39 & 0.388 & 0.086 & 1.42 & 0.347 & 0.074 & 1.63 \\
\hline Two Employed Friends & 0.357 & 0.079 & 1.35 & 0.383 & 0.085 & 1.45 & 0.360 & 0.080 & 1.36 & 0.411 & 0.091 & 1.52 & 0.382 & 0.081 & 1.72 \\
\hline Three Employed Friends & 0.636 & 0.141 & 2.21 & 0.656 & 0.145 & 2.29 & 0.636 & 0.141 & 2.21 & 0.694 & 0.154 & 2.37 & 0.678 & 0.144 & 2.74 \\
\hline Log-Likelihood & & -449.32 & & & -452.50 & & & -449.40 & & & -437.21 & & & -607.82 & \\
\hline Number of Observations & & 1,324 & & & 1,324 & & & 1,324 & & & 1,307 & & & 1,787 & \\
\hline
\end{tabular}

Notes: Fixed effect regressions for the transition from non-employment to employment. Other regressors include individual and friend time-varying covariates (age, local unemployment rate at travel-to-work area, dummies for living as a couple, number of children (1, 2 or more), having health problems, experiencing depression, smoking, time dummies, and age of each friend. FE-1 is the main specification with the full set of covariates and FE-2 is estimated without individual time-varyimg covariates. FE-3 is estimated without the local unemployment rate. Estimation FE-4 includes a control for the length of the non-employment spell. Estimation FE-5 is based on the sample of individuals which includes those who have missing information on their friends. Dummy variables defined by the type of information missing are included as additional regressors. The full specification of FE-1 is reported in Table A1. 
Table 4: Endogenous Network.

Dependent Variable:

Number of Employed Friends

FE

\begin{tabular}{lcc} 
& Coef. & t-ratio \\
Duration in Non-Employment & -0.0004 & -1.31 \\
(in months) & & \\
Number of Observations & 6,423 \\
\hline & \\
\cline { 2 - 2 }
\end{tabular}

Dependent Variable:

Job Finding Probability

$\begin{array}{lccc} & \text { Coef. } & \text { M.E } & \text { t-ratio } \\ \text { Lag Number of Employed Friends } & 0.276 & 0.063 & 2.57\end{array}$

Number of Observations 795

Note: The top panel reports the coefficient estimate of the linear fixed-effects regression of the number of employed friends on the duration in nonemployment. The second panel reports the estimate of the conditional fixedeffects regression of the probability of finding a job on the lag number of employed friends. Both estimations include all the other controls. 
Table 5. Labor Market Outcomes.

\begin{tabular}{|c|c|c|c|c|c|}
\hline \multirow[b]{3}{*}{ Number of Employed Friends } & \multirow{2}{*}{\multicolumn{2}{|c|}{$\frac{\text { Wages }}{\text { Coef. t-ratio }}$}} & \multicolumn{3}{|c|}{ Exit Employment } \\
\hline & & & Coef. & M.E. & t-ratio \\
\hline & 0.062 & 4.10 & -0.350 & -0.051 & -3.58 \\
\hline \multirow[t]{3}{*}{ Number of Observations } & \multicolumn{2}{|c|}{1,093} & \multicolumn{3}{|c|}{1,062} \\
\hline & \multicolumn{2}{|c|}{ Wages } & \multicolumn{3}{|c|}{ Exit Employment } \\
\hline & Coef. & t-ratio & Coef. & M.E. & t-ratio \\
\hline One Employed Friend & 0.116 & 2.04 & -0.316 & -0.046 & -0.89 \\
\hline Two Employed Friends & 0.201 & 3.76 & -0.632 & -0.093 & -1.84 \\
\hline Three Employed Friends & 0.222 & 4.20 & -1.034 & -0.152 & -2.86 \\
\hline Number of Observations & \multicolumn{2}{|c|}{1,093} & \multicolumn{3}{|c|}{1,062} \\
\hline
\end{tabular}

Notes: The estimation in the first column is a linear regression of log wages for the sample of those who make a transition from non-employment to employment. The estimation in the second column is a logit regression for the probability to exit from employment in the following year for the sample of those who make a transition from non-employment to employment. 
Table 6. Life and Leisure Satisfaction.

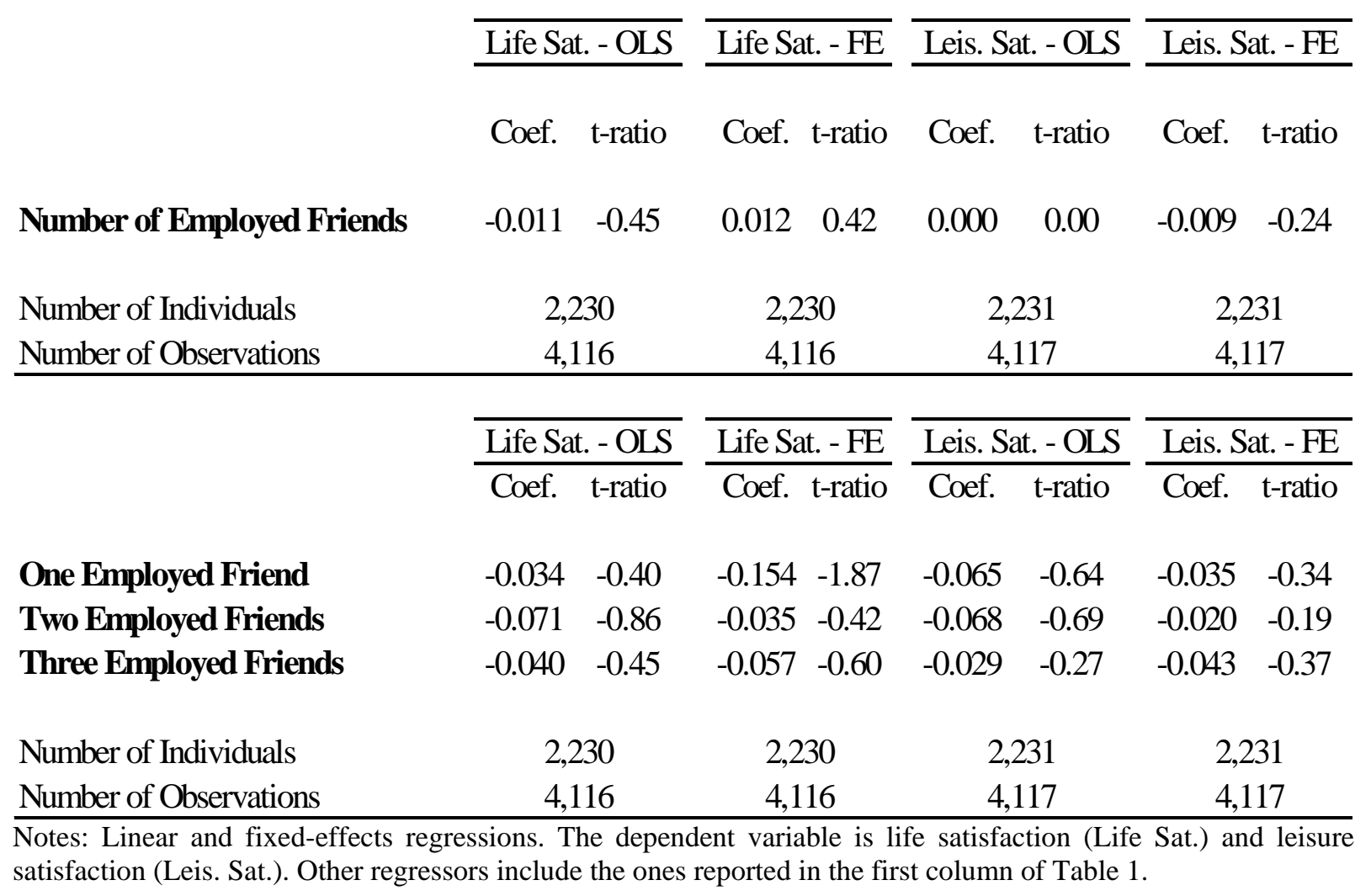


Table A1. Full Specification Estimates

\begin{tabular}{|c|c|c|c|c|c|c|}
\hline \multirow{4}{*}{$\begin{array}{l}\text { Number of Employed Friends } \\
\text { Individual Characteristics }\end{array}$} & \multicolumn{3}{|c|}{ Pooled Logit } & \multicolumn{3}{|c|}{ Fixed Effects } \\
\hline & Coef. & S.Error & t-ratio & \multirow{2}{*}{$\frac{\text { Coef. }}{0.166}$} & \multirow{3}{*}{$\frac{\text { S.Error }}{0.082}$} & \multirow{2}{*}{$\frac{\text { t-ratio }}{2.04}$} \\
\hline & 0.373 & 0.041 & 9.16 & & & \\
\hline & & & & & & \\
\hline Female & -0.598 & 0.137 & -4.38 & & & \\
\hline Age & -0.068 & 0.005 & -13.21 & 0.060 & 0.303 & 0.20 \\
\hline Having Health Problems & -0.360 & 0.076 & -4.73 & -0.154 & 0.172 & -0.90 \\
\hline Experiencing Depression & -0.528 & 0.131 & -4.02 & -0.586 & 0.256 & -2.29 \\
\hline Smoking & 0.008 & 0.085 & 0.09 & 0.064 & 0.277 & 0.23 \\
\hline \multicolumn{7}{|l|}{ Family Characteristics } \\
\hline In Couple & 0.221 & 0.096 & 2.29 & 0.290 & 0.254 & 1.14 \\
\hline One Child & -0.151 & 0.111 & -1.36 & -0.146 & 0.277 & -0.52 \\
\hline Two Children & -0.156 & 0.109 & -1.44 & -0.018 & 0.301 & -0.06 \\
\hline Three or more Children & -0.447 & 0.130 & -3.43 & -0.186 & 0.369 & -0.50 \\
\hline \multicolumn{7}{|l|}{ Level of Education } \\
\hline Other Qualifications & 0.383 & 0.142 & 2.69 & & & \\
\hline O-Level & 0.259 & 0.125 & 2.08 & & & \\
\hline A-Level & 0.476 & 0.143 & 3.33 & & & \\
\hline Other Higher Education & 0.727 & 0.121 & 6.01 & & & \\
\hline University Degree & 0.990 & 0.153 & 6.46 & & & \\
\hline \multicolumn{7}{|l|}{ Regions } \\
\hline Inner London & -0.910 & 0.496 & -1.84 & & & \\
\hline Outer London & -0.629 & 0.478 & -1.32 & & & \\
\hline Rest of South East & -0.343 & 0.450 & -0.76 & & & \\
\hline South West & -0.386 & 0.460 & -0.84 & & & \\
\hline East Anglia & -0.412 & 0.472 & -0.87 & & & \\
\hline East Midlands & -0.611 & 0.453 & -1.35 & & & \\
\hline West Midlands Conurbation & -0.679 & 0.488 & -1.39 & & & \\
\hline Rest of West Midlands & -0.565 & 0.473 & -1.19 & & & \\
\hline Greater Manchester & -0.494 & 0.489 & -1.01 & & & \\
\hline Merseyside & -1.378 & 0.522 & -2.64 & & & \\
\hline Rest of North West & -0.674 & 0.477 & -1.41 & & & \\
\hline South Yorkshire & -0.920 & 0.506 & -1.82 & & & \\
\hline West Yorkshire & -0.886 & 0.482 & -1.84 & & & \\
\hline Rest of Yorkshire & -0.513 & 0.481 & -1.07 & & & \\
\hline Tyne and Wear & -0.884 & 0.504 & -1.75 & & & \\
\hline Rest of North & -0.558 & 0.475 & -1.18 & & & \\
\hline Wales & -0.611 & 0.467 & -1.31 & & & \\
\hline Scotland & -0.542 & 0.464 & -1.17 & & & \\
\hline
\end{tabular}




\begin{tabular}{|c|c|c|c|c|c|c|}
\hline \multicolumn{7}{|l|}{ Ethnicity } \\
\hline White & -1.310 & 1.458 & -0.90 & & & \\
\hline Black Carribean & -1.672 & 1.560 & -1.07 & & & \\
\hline Black African & -1.355 & 1.586 & -0.85 & & & \\
\hline Black Other & -0.426 & 1.694 & -0.25 & & & \\
\hline Indian & -1.280 & 1.500 & -0.85 & & & \\
\hline Pakistani & -2.337 & 1.572 & -1.49 & & & \\
\hline Bangladeshi & -2.066 & 1.603 & -1.29 & & & \\
\hline Other & -1.292 & 1.553 & -0.83 & & & \\
\hline Local Unemployment Rate & -0.025 & 0.015 & -1.66 & 0.026 & 0.070 & 0.37 \\
\hline w4 & 0.072 & 0.116 & 0.63 & 0.426 & 0.640 & 0.67 \\
\hline w6 & -0.142 & 0.158 & -0.90 & 0.452 & 1.250 & 0.36 \\
\hline w8 & -0.190 & 0.200 & -0.95 & 0.493 & 1.868 & 0.26 \\
\hline w10 & -0.030 & 0.212 & -0.14 & 0.357 & 2.465 & 0.14 \\
\hline w12 & -0.216 & 0.225 & -0.96 & -0.225 & 3.067 & -0.07 \\
\hline w14 & -0.207 & 0.233 & -0.89 & -0.116 & 3.666 & -0.03 \\
\hline \multicolumn{7}{|l|}{ Friends' Characteristics } \\
\hline Age of Friend 1 & 0.006 & 0.004 & 1.64 & 0.015 & 0.008 & 1.87 \\
\hline Age of Friend 2 & 0.001 & 0.004 & 0.24 & 0.007 & 0.008 & 0.78 \\
\hline Age of Friend 3 & -0.001 & 0.004 & -0.17 & 0.005 & 0.008 & 0.65 \\
\hline Friend 1 - Male & 0.044 & 0.101 & 0.43 & & & \\
\hline Friend 2 - Male & -0.162 & 0.095 & -1.71 & & & \\
\hline Friend 3 - Male & -0.165 & 0.086 & -1.92 & & & \\
\hline Constant & 2.842 & 1.557 & 1.83 & & & \\
\hline Log-Likelihood & \multicolumn{3}{|c|}{$-2,742.21$} & \multicolumn{3}{|c|}{-450.04} \\
\hline Number of Individuals & \multicolumn{3}{|c|}{3,196} & \multicolumn{3}{|c|}{437} \\
\hline Number of Observations & \multicolumn{3}{|c|}{6,479} & \multicolumn{3}{|c|}{1,324} \\
\hline
\end{tabular}

Notes: The pooled logit estimation refers to the estimation in the third column of Table 2. The fixed effects estimation refers to the estimation in the first column of Table 3 (FE-1). 